\title{
POLÍTICAS PÚBLICAS DE ENSINO SUPERIOR NO BRASIL: UM OLHAR SOBRE O ACESSO E A INCLUSÃO SOCIAL
}

\author{
POLÍTICAS PÚBLICAS DE ENSEÑANZA SUPERIOR EN BRASIL: UNA \\ MIRADA SOBRE EL ACCESO Y LA INCLUSIÓN SOCIAL
}

\author{
PUBLIC POLICIES OF HIGHER EDUCATION IN BRAZIL: A VIEW ON \\ ACCESS AND SOCIAL INCLUSION
}

\author{
Luci Annee VARGAS CARNEIRO ${ }^{1}$ \\ Fabiane Romano de Souza BRIDI ${ }^{2}$
}

\begin{abstract}
RESUMO: Este artigo é fruto de uma pesquisa qualitativa do tipo bibliográfica que se propõe a discutir o percurso histórico das políticas públicas de Ensino Superior no Brasil, com foco na expansão e interiorização deste nível de ensino. Problematiza algumas implicações das mesmas através do levantamento de referências sobre a temática em publicações acadêmicas e textos oficiais. Os resultados apontam para um expressivo investimento na ampliação do acesso que culminou com o aumento significativo de vagas em instituições públicas e privadas, atingindo um público antes excluído, e fragilidades no que tange ao apoio necessário para a permanência e garantia de aprendizagem destes estudantes. Em virtude do déficit histórico no acesso ao Ensino Superior no país, conclui-se que se faz necessário a manutenção desta referida ampliação aliada a programas de assistência estudantil que garantam o suporte necessário ao processo acadêmico e de profissionalização dos estudantes universitários.
\end{abstract}

PALAVRAS-CHAVE: Políticas públicas. Ensino superior. Acesso. Inclusão social.

RESUMEN: Este artículo es fruto de una investigación cualitativa del tipo bibliográfica que se propone discutir el recorrido histórico de las políticas públicas de Enseñanza Superior en Brasil con foco en la expansión e interiorización de este nivel de enseñanza. Problematiza algunas implicaciones de las mismas a través del levantamiento de referencias sobre la temática en publicaciones académicas y textos oficiales. Los resultados apuntan a una expresiva inversión en la ampliación del acceso que culminó con el aumento significativo de vacantes en instituciones públicas y privadas alcanzando un público antes excluido y fragilidades en lo que se refiere al apoyo necesario para la permanencia y garantía de aprendizaje de estos estudiantes. En virtud del déficit histórico en el acceso a la Enseñanza Superior en el país, se concluye que se hace necesario el mantenimiento de esta referida ampliación aliada a programas de asistencia estudiantil que garanticen el soporte necesario al proceso académico y de profesionalización de los estudiantes universitarios.

${ }^{1}$ Universidade Federal do Pampa (UNIPAMPA), Bagé - RS - Brasil. Mestre em Políticas Públicas e Gestão Educacional e Pedagoga - Técnica Administrativa em Educação-TAE. OrcID: https://orcid.org/0000-0003-46296241. E-mail: vargascarneiro@gmail.com

2 Universidade Federal de Santa Maria (UFSM), Santa Maria - RS - Brasil. Professora Adjunta do Departamento de Educação Especial e do Programa de Pós-Graduação em Educação da Universidade Federal de Santa Maria; coordena o Núcleo de Estudos e Pesquisa sobre Escolarização e Inclusão (NUEPEI) e atua nas áreas da educação, educação especial e psicopedagogia, com ênfase nos processos inclusivos. OrcID: http://orcid.org/0000-0002-8727-851X. E-mail: fabianebridi@gmail.com 
PALABRAS CLAVE: Políticas públicas. Enseñanza superior. Acceso. Inclusión social.

ABSTRACT: This article it's fruit of a qualitative research of the bibliographic type that proposes to discuss the historical course of public policies of Higher Education in Brazil with a focus on the expansion and interiorization of this level of education. It problematizes some of the implications of the same through the survey of references on the subject in academic publications and official texts. The results point to a significant investment in the expansion of access that culminated with the significant increase of vacancies in public and private institutions reaching a previously excluded public and weaknesses regarding the necessary support for the permanence and guarantee of learning of these students. Due to the historical deficit in the access to Higher Education in the country, it is concluded that it is necessary to maintain this expansion, coupled with student assistance programs that guarantee the necessary support for the academic process and professionalization of university students.

KEYWORDS: Public policies. Higher education. Access. Social inclusion.

\section{Introdução}

$\mathrm{O}$ estudo aqui apresentado tem como objetivo discutir o percurso histórico das políticas públicas de Ensino Superior no Brasil, com foco nas políticas de expansão e interiorização deste nível de ensino. Para tal, foi realizada uma pesquisa bibliográfica: "procurando referências teóricas publicadas com o objetivo de recolher informações ou conhecimentos prévios sobre o problema a respeito do qual se procura a resposta" (FONSECA, 2002, p. 32). Os dados produzidos foram organizados em dois eixos analíticos: o primeiro envolvendo uma dimensão histórica das políticas de Ensino Superior no país desde o Brasil Colônia até o final dos anos 90, utilizando-se das contribuições teóricas de Dourado (2001,2011), Fávero (1999), Santos; Cerqueira (2009) e Vieira (2007). O segundo eixo centrou-se na análise das políticas de ampliação do acesso adotadas a partir dos anos 2000 e suas possíveis implicações a partir das contribuições de Dourado (2001,2011), Santos; Cerqueira (2009), Simões; Mello Neto (2012) e Vieira (2007), além de textos oficiais sobre os programas e ações governamentais de expansão do Ensino Superior.

O cenário do Ensino Superior no Brasil alterou-se significativamente na última década, como resultado de políticas públicas de ampliação do acesso implantadas pelo governo federal. O aumento no quantitativo de vagas possibilitou o ingresso na Universidade de camadas antes excluídas deste nível de ensino. No entanto, os números ainda não são próximos do ideal, considerando que expressivo quantitativo da população brasileira continua fora do Ensino Superior. Para os que acessam, emerge a problemática qualidade e 
permanência, uma vez que o acesso não é suficiente, é preciso garantir o desenvolvimento do estudante em seu percurso acadêmico, visando seu ingresso no mundo profissional.

O Ensino Superior no Brasil caracterizou-se tradicionalmente por ser excludente, aos mais bem preparados estavam disponíveis as vagas das instituições públicas e aos mais ricos as mais conceituadas instituições privadas. Aos pobres e assalariados as possibilidades eram mínimas e ficavam condicionadas estritamente a um grande esforço individual. Este cenário sofreu modificações importantes em virtude de políticas públicas federais tais como o Programa de Apoio a Planos de Reestruturação e Expansão das Universidades Federais (REUNI) e o Programa Universidade para Todos (PROUNI). É sabido que estas políticas carregam o peso do projeto neoliberal que fundamenta boa parte de toda essa expansão recente do Ensino Superior no Brasil, mesmo assim, estas trazem, também, impactos positivos no âmbito da inclusão social.

\title{
Percurso histórico das políticas públicas de Ensino Superior no Brasil
}

Diferentemente do que ocorreu em colônias espanholas na América Latina, no Brasil o surgimento da Universidade é tardio. A criação de faculdades isoladas surge como uma política imperial instalada apenas com a vinda da Família Real Portuguesa para o Brasil em 1808, visando à formação dos quadros para atendimento de demandas da corte. Somente na década de 1920 foi finalmente criada a primeira Universidade brasileira, a Universidade do Rio de Janeiro.

\begin{abstract}
Apoiado na Reforma de 1915, O Governo Federal cria, em 1920, através do Decreto n. ${ }^{\circ}$ 24.343, a primeira instituição universitária no País, a Universidade do Rio de Janeiro, sendo o Reitor e os diretores das unidades nomeados pelo Presidente da República. O controle sobre as universidades federais, a partir daí, torna-se cada vez mais explícito. Com a reforma do Ensino Superior promovida pelo Ministro Francisco Campos, em 1931, um ponto bastante acentuado é a concessão da autonomia relativa à universidade, como uma preparação para a autonomia plena. Apesar da justificativa de não ser possível, naquele momento, conceder-lhes "autonomia plena", tanto no plano didático, como no administrativo, a questão ficou, a rigor, em aberto. (FÁVERO, 1999, p. 2).
\end{abstract}

Para Dourado (2011), o desenvolvimento do Ensino Superior no país, desde o princípio, se dá a partir de políticas e condições objetivas que permitem o desenvolvimento e coexistência de faculdades isoladas, institutos e Universidades, porém estas últimas em menor escala. Argumenta que o complexo cenário do Ensino Superior no Brasil se desenha marcado fortemente pelo embate entre defensores do ensino público e do ensino privado. Segundo o 
mesmo autor, na década de 50 e início da década de 60 são federalizadas Instituições de Ensino Superior (IES) e criadas universidades federais públicas, sendo este um momento importante para a história da Educação Superior.

Em sequência, o período do Regime Militar ganha destaque no histórico brasileiro pelo desenvolvimento de condições que levaram à ampliação do Ensino Superior no país, porém, na esfera privada. Houve aumento da demanda por educação superior associada ao crescimento das camadas médias e aumento de oportunidades de trabalho com a modernização da economia e máquina estatal, com o denominado 'milagre econômico'. (SANTOS; CERQUEIRA, 2009).

O setor público não atendeu esta demanda por falta de estrutura e planejamento, porém, o setor privado foi capaz de absorvê-la, concentrando-se na oferta de cursos de baixo custo e no estabelecimento de exigências acadêmicas menores, tanto para o ingresso como para o prosseguimento dos estudos. "As instituições privadas de ensino superior tornaram-se um grande negócio". (SANTOS; CERQUEIRA, 2009, p.6).

Os militares, apoiados em um modelo desenvolvimentista de país e inspirados no sistema americano, firmaram um acordo entre o Ministério da Educação (MEC) e a United States Agency for International Development (USAID), com a finalidade de introduzir reformas no sistema educacional brasileiro em todos os níveis. Como consequência deste acordo foram implementadas mudanças na estrutura universitária através da Lei $\mathrm{n}^{\circ}$. 5540/68 e dispositivos complementares.

Os pressupostos da reforma envolveram a qualificação da mão de obra para o mercado de trabalho, a produtividade e a interação com as empresas. O referido acordo gerou mudanças em todos os níveis de ensino da educação pública brasileira. (DOURADO, 2001; VIEIRA 2007).

Segundo Santos; Cerqueira (2009, p. 5):

A reforma dos militares continha basicamente as seguintes mudanças: extinção da cátedra; fim da autonomia das faculdades; criação de institutos, faculdades e/ou escolas; introdução do sistema de créditos; ciclo básico antes da formação profissional; garantia da representação discente e docente; ingresso contínuo por carreiras e currículos mínimos fixados pelo MEC (não à flexibilização).

A ampliação do acesso se deu nos cursos tradicionais, na organização da rede federal; no estímulo à pesquisa e na qualificação pela Capes e pelo $\mathrm{CNPq}$; foi criado um programa modular de apoio à pós-graduação e à pesquisa e a introdução do regime de tempo integral para docentes. 
Decorre desta reforma a institucionalização da pós-graduação pública e a criação de universidades federais em regime fundacional. No entanto, as mudanças propostas pelos militares não foram implementadas integralmente, as reformas curriculares não foram significativas e a ampliação de vagas ocorreu apenas na multiplicação de matrículas em cursos tradicionais, sem atingir a demanda necessária.

A década de 80 é marcada pelo processo de abertura política, a nova Constituição em 1988 afirma para a Educação Superior o princípio da autonomia, embora o mesmo não tenha sido implementado de imediato. A Constituição Federal afirma princípios de uma universidade como dever do Estado, privilegia a produção do conhecimento de forma integrada ao ensino, acrescenta a extensão a esta integração e consagra o princípio da indissociabilidade entre ensino, pesquisa e extensão nas universidades. (VIEIRA, 2007).

Registra-se também um processo de contenção da expansão da educação privada por parte do então Conselho Federal de Educação (CEF), sem, contudo, conseguir conter a lógica já instaurada de expansão deste setor. O sistema de Ensino Superior público sofre com a crise econômica instalada na América Latina e com a crise política nacional diante da abertura democrática. São anos marcados pelo sub-financiamento, grandes greves de professores, técnicos e alunos, estagnação na oferta de vagas, graves problemas administrativos, entre outras consequências negativas. (DOURADO, 2001, 2011).

A retomada do avanço no processo de massificação do Ensino Superior privado caracteriza a década de 90 . Este processo deu-se por meio de regulamentações estatais que efetivaram a diversificação das formas de organização das instituições com a flexibilização nos processos de criação de IES como centros universitários, faculdades, faculdades integradas e institutos. Neste processo proliferam-se as instituições não universitárias. Ocorreu expressivo investimento do governo no financiamento do setor privado, com recursos do Banco Nacional de Desenvolvimento Econômico e Social (BNDES) para as IES, para financiamento estudantil - crédito educativo e Fundo de Financiamento ao Estudante do Ensino Superior (FIES) ${ }^{3}$. Neste contexto, a década é marcada também pelo congelamento de investimentos e salários nas universidades públicas, gerando precarização do trabalho nas universidades. Tais políticas são características da reforma do Estado proposta pelo governo, numa perspectiva de redução da ação estatal em políticas públicas sociais pautada pelas regulações estabelecidas por instituições internacionais, como o Banco Mundial.

3 O FIES é um programa do Ministério da Educação destinado a financiar estudantes de cursos de graduação regularmente matriculados em instituições de ensino privadas cadastradas no programa. 
Por meio de diferentes dinâmicas e políticas, o cenário da educação superior, sobretudo, após 1995, vai-se traduzir por regulamentações pelo poder público federal, de maneira centralizada, sobretudo para as instituições públicas federais e privadas. Tais dispositivos legais vão naturalizar a diversificação e diferenciação da educação superior e contribuir para a intensificação dos processos de expansão das IES, sobretudo do setor privado, numa escala sem precedentes na educação nacional e, ao mesmo tempo, contribuir para a alteração da lógica e das dinâmicas organizativas das IES públicas, principalmente as federais. (DOURADO, 2011, p.56).

Cabe destacar ainda na década de 90 a nova Lei de Diretrizes e Bases da Educação Nacional (LDB) 9.394/96. Segundo Vieira (2007), esta lei introduziu um conjunto de modificações importantes no sistema educacional brasileiro. No tocante à Educação Superior, destaca-se: regulamentação de formas diferenciadas de processo seletivo, inclusão de diretrizes curriculares para os cursos de graduação, diferenciação institucional introduzida pelo artigo $45^{4}$ desta lei e regulamentada pelo Decreto $n^{\circ} 2.306 / 97^{5}$.

Outras regulamentações trazidas pela LDB impactam diretamente no Ensino Superior: gratuidade do ensino público em todos os níveis, embora em alguns casos de pós-graduação esse dispositivo não tenha se concretizado; gestão democrática do ensino público; indissociabilidade entre ensino, pesquisa e extensão, autonomia universitária.

Em sequência, já nos anos 2000 teremos o Plano Nacional de Educação aprovado em 2001, trazendo alguns indicadores para a Educação Superior, a saber: diversificação do sistema por meio de políticas de expansão da educação superior; não ampliação de recursos vinculados ao governo federal para esse nível de ensino; aferição da qualidade de ensino mediante sistema de avaliação (cabe ressaltar aqui a ênfase no produto em relação ao processo, seguindo uma lógica do cenário mundial); destaque para o papel da educação a distância. Para Dourado (2011, p. 57), a ausência de "mecanismos concretos de financiamento, $[\ldots]$ contribuíram para a consolidação de novos formatos de privatização desse nível de ensino, respaldada pela interpenetração entre as esferas pública e privada”.

O Brasil adentra o século XXI com um grande déficit de vagas no Ensino Superior. A mercantilização deste nível de ensino promovida pelas estratégias neoliberais continua a dominar o cenário nacional. As políticas governamentais de universalização da Educação Básica geraram uma demanda latente para a Educação Superior no país. A União, responsável

\footnotetext{
${ }^{4}$ Art. 45. A educação superior será ministrada em instituições de ensino superior, públicas ou privadas, com variados graus de abrangência ou especialização.

${ }^{5}$ Regulamenta para o Sistema Federal de Ensino, as disposições contidas no art. 10 da Medida Provisória $n^{\circ}$ 1.477-39, de 8 de agosto de 1997, e nos arts. 16, 19, 20, 45, 46 e $\S 1^{\circ}, 52$, parágrafo único, 54 e 88 da Lei n ${ }^{\circ}$ 9.394, de 20 de dezembro de 1996, e dá outras providências. Revogado pelo Decreto nº 3.860/2001, de 9 de julho de 2001, que dispõe sobre a organização do ensino superior, a avaliação de cursos e instituições, e dá outras providências.
} 
por fomentar o Ensino Superior, conforme preconizam a Constituição Federal e a LDB, não conseguiu criar condições para absorção de estudantes que concluem o Ensino Médio anualmente e de uma expressiva demanda acumulada. Entretanto, neste período houve grande cobrança do mercado por profissionais capacitados a nível superior e também da sociedade pela ampliação de vagas, fatores que contribuirão para as políticas públicas do início dos anos 2000.

\section{Políticas públicas de expansão e interiorização do Ensino Superior no Brasil}

A partir do governo do Presidente Luís Inácio da Silva (2003-2010), pode-se observar a significativa implementação de políticas públicas de Ensino Superior voltadas para a ampliação do acesso. Este governo trabalhou com um conjunto de novas políticas, assim como deu continuidade e ampliou ações do governo do Presidente Fernando Henrique Cardoso (1995-2003).

Quanto à referida manutenção de políticas destaca-se: incremento no recente sistema de avaliação das IES; fortalecimento do Exame Nacional do Ensino Médio (ENEM); ampliação do FIES, entre outras. A necessidade de elevar os índices de escolaridade da população, as demandas do mercado por mão de obra qualificada aliadas à conjuntura internacional são elementos propulsores das políticas de ambos os governos citados.

De acordo com dados do Relatório Técnico do Censo da Educação Superior (BRASIL, 2014), o total de alunos matriculados atingiu 7,3 milhões em 2013, um crescimento estimado em quase 300 mil matrículas em comparação com 2012. No período compreendido entre 2012 a 2013, as matrículas em IES acenderam 3,8\%, com crescimento de 1,9\% na rede pública e 4,5\% na rede privada. O panorama universitário aponta 32 mil cursos de graduação, distribuídos em 2,4 mil instituições de ensino superior, sendo 301 públicas e 2 mil particulares. Percebe-se que apesar do incremento da atuação pública neste setor, o ensino privado propaga-se acentuadamente.

Ainda de acordo com o referido censo, as universidades concentram 53,4\% das matrículas e as faculdades ficam com $29,2 \%$, sendo as demais matrículas distribuídas entre centros universitários e institutos federais. O número de ingressantes em cursos de graduação aumentou 76,4\% considerando-se o período 2003 até 2013. Embora expressivo o aumento percentual no acesso na última década, os números indicam que apenas cerca de $30 \%$ da população brasileira na faixa etária de 18 a 24 anos está cursando este nível de ensino. (BRASIL, 2014). 
Segundo Carmo e colaboradores (2014), o crescimento contínuo do ensino superior privado ocorreu para atender a constante demanda da sociedade por cursos universitários. Para estes autores, desde a década de 1990 a ampliação do acesso ao Ensino Superior se deu, essencialmente, pela ampla abertura de novas IES privadas, principalmente faculdades. Analisando o período de 2001 a 2010, os pesquisadores registram um salto na atuação privada de 1.208 instituições em 2001 para 2.100 em 2010, crescimento de 74\% em uma década. Em quantitativo de alunos, o crescimento foi de mais de $126 \%$, considerando o mesmo período.

Resguardados os impactos positivos para a inclusão social, diminuição de desigualdades e para o desenvolvimento educacional, é importante destacar que parte das políticas atuais fortaleceram uma lógica mercadológica da Educação Superior, gerando competitividade entre as IES públicas, e também seguiram a fortalecer o Ensino Superior privado com a utilização de recursos públicos.

Com base nos autores: Vieira (2007), Santos; Cerqueira (2009), Dourado (2001,2011), Simões e Mello Neto (2012), bem como a partir da leitura de textos oficiais disponíveis na página do MEC, elencam-se abaixo as principais políticas atuais para o Ensino Superior, focadas na ampliação do acesso:

a) Incremento do financiamento das instituições de ensino federais através da ampliação de recursos, principalmente na política de expansão e interiorização das instituições federais, por meio de vários mecanismos, como:

1. Criação de extensões das Universidades Federais em cidades do interior;

2. Criação de novas universidades federais;

3. Expansão e transformação de Centros Federais de Educação Tecnológica (CEFETs) em Institutos Federais de Educação Tecnológica (IFETs), com a decorrente criação de novos cursos;

4. Programa de Apoio a Planos de Reestruturação das Universidades Federais (REUNI), que tem como principal objetivo ampliar o acesso e a permanência na Educação Superior. O Reuni foi instituído pelo Decreto $\mathrm{n}^{\circ}$. 6.096, de 24 de abril de 2007, como uma das ações que integram o Plano de Desenvolvimento da Educação (PDE);

b) Abertura de vagas para docentes e técnicos administrativos nas instituições públicas federais visando à consolidação dessas instituições e possibilitando condições para a expansão de vagas e cursos, bem como a interiorização de parcela dessas IES; 
c) Institucionalização, por meio do Decreto $\mathrm{n}^{\circ} 5.800$, de 8 de junho de 2006 , do Sistema Universidade Aberta do Brasil (UAB), direcionada à expansão e interiorização de cursos e programas, por meio da modalidade de educação a distância no país. Tal processo propiciou alterações substantivas nas Instituições Federais de Ensino Superior (IFES) à medida que estas institucionalizaram políticas de regulamentação e ampliação da EAD;

d) Reestruturação das políticas de financiamento da Educação Superior privada por meio do:

1. Programa Universidade para Todos (PROUNI), instituído pela Medida Provisória (MP) $n^{\circ}$. 213, de 10 de setembro de 2004, convertida posteriormente na Lei $\mathrm{n}^{\mathrm{o}}$. 11.096 de 2004. Este programa surge com o objetivo de regular a atuação de entidades beneficentes de assistência social no Ensino Superior no que se refere à isenção fiscal das IES, além de promover o ingresso de estudantes oriundos da rede pública de ensino na educação superior. De acordo com dados de 2012 do Sistema do PROUNI (SISPROUNI), ao longo dos primeiros anos de existência, o programa já garantiu o acesso ao Ensino Superior a mais de um milhão de bolsistas brasileiros de baixa renda;

e) Reestruturação das políticas de financiamento da Educação Superior privada por meio do:

1. Programa Universidade para Todos (PROUNI), instituído pela Medida Provisória (MP) $\mathrm{n}^{\circ}$. 213, de 10 de setembro de 2004, convertida posteriormente na Lei $\mathrm{n}^{\mathrm{o}}$. 11.096 de 2004. Este programa surge com o objetivo de regular a atuação de entidades beneficentes de assistência social no Ensino Superior no que se refere à isenção fiscal das IES, além de promover o ingresso de estudantes oriundos da rede pública de ensino na educação superior. De acordo com dados de 2012 do Sistema do PROUNI (SISPROUNI), ao longo dos primeiros anos de existência, o programa já garantiu o acesso ao Ensino Superior a mais de um milhão de bolsistas brasileiros de baixa renda;

2. Aperfeiçoamento e ampliação do FIES. A partir de 2010, o fundo passou a ser operado pelo Fundo Nacional de Desenvolvimento da Educação (FNDE), as mudanças abarcaram redução de juros e maior facilidade para liberação dos financiamentos aos estudantes das IES privadas; aperfeiçoamento e ampliação do FIES. A partir de 2010, o fundo passou a ser operado pelo Fundo Nacional de Desenvolvimento da Educação (FNDE), as mudanças abarcaram redução de juros e maior facilidade para liberação dos financiamentos aos estudantes das IES privadas; aperfeiçoamento e ampliação do FIES. A partir de 2010, o fundo passou a ser operado pelo Fundo Nacional de Desenvolvimento da Educação (FNDE), as mudanças abarcaram redução de juros e maior 
facilidade para liberação dos financiamentos aos estudantes das IES privadas;

f) Política de cotas: o Programa de Cotas das Universidades e Instituições de Ensino Técnico e Médio Federais, instituído pela Lei n. 12.711, de 29 de agosto de 2012, dispõe sobre o ingresso nas universidades federais e nas instituições federais de ensino técnico de nível médio, regulamentada pelo Decreto no 7.824 de 11 de outubro de 2012. A partir destas normativas, garantiu-se que a metade das vagas de todos os cursos das instituições federais sejam reservadas a alunos que estudaram todo o nível médio em escola pública. Uma parte dessas vagas é reservada a pardos, negros e índios, outra parte aos estudantes com renda familiar igual ou menor que 1,5 salário mínimo per capita;

g) Universalização do ENEM e criação do Sistema de Seleção Unificada (Sisu). O ENEM, ao longo dos últimos anos, tornou-se um instrumento de exame nacional de seleção para diversas universidades, praticamente substituindo o vestibular. O Sisu é o sistema informatizado, gerenciado pelo MEC, pelo qual instituições públicas de educação superior oferecem vagas a candidatos aprovados no ENEM. Através deste sistema as vagas são disponibilizadas de forma ampla e democrática, possibilitando a estudantes de qualquer lugar do país acesso às vagas ofertadas pelas universidades públicas participantes do Sisu, mediante seleção por rendimento no ENEM. A dinâmica de chamadas do Sisu possibilita aos candidatos irem administrando suas chances de ingresso ao Ensino Superior conforme seus interesses e condições, além de permitir o gerenciamento de outras formas de ingresso, como: PROUNI, FIES, vestibulares ou outras seleções;

h) Efetivação de apoio e programas direcionados à diversidade, com especial destaque às ações afirmativas (cotas, assistência estudantil, entre outros). Podemos destacar aqui o Plano Nacional de Assistência Estudantil (PNAES), que objetiva a permanência de estudantes de baixa renda matriculados em cursos de graduação presencial das instituições federais de ensino superior, e o Programa INCLUIR, que visa dotar as IFES de infraestrutura adequada ao ingresso e à permanência da pessoa com deficiência, ambos através de aporte financeiro às IES públicas;

É importante ressaltar que os programas de apoio voltados à assistência estudantil e ações afirmativas, bem como os recursos para estes destinados, são insuficientes para dar conta das necessidades do grande número de estudantes que agora ingressa no Ensino Superior. Embora fortemente presentes no discurso oficial, as ações de apoio ao estudante 
universitário em suas necessidades educativas e sociais não acompanharam ainda o ritmo da democratização do acesso.

Apesar do inegável avanço em relação à oportunidade do acesso do estudante ao Ensino Superior, seria um reducionismo considerar indiscriminadamente o acesso como sucesso escolar (ZAGO, 2006). A este respeito aponta Oliveira (2000): “Elimina-se, assim, a exclusão da escola, não a exclusão do acesso ao conhecimento, criando-se condições historicamente novas para demandas por qualidade de ensino". (OLIVEIRA, 2000, p. 92).

Simões e Mello Neto (2012, p. 5) refletem sobre o impacto dessas recentes políticas de modo bastante interessante:

\begin{abstract}
No imaginário popular tais programas são a certeza de uma nova possibilidade de acesso a espaços que nunca haviam sido "disputáveis" à maior parte da população brasileira, pois se apresentam ao menos como bandeira aparente, na defesa da igualdade de oportunidades de acesso para todos. Ao financiar a educação superior aos estudantes de baixa renda e garantir o acesso a vagas - sejam elas públicas ou privadas - a indivíduos que antes não teriam esta oportunidade, faz crer que funcionará como um mecanismo de garantia para que todo e qualquer estudante tenha acesso à educação superior de qualidade. Entretanto, estes Programas não trazem em sua origem uma rediscussão do papel da Educação Superior no Brasil e não se propõem a observar o real impacto de tais políticas na educação brasileira como um todo, assim como não observam as possíveis transformações causadas por um inédito acesso ao ES em estudantes contemplados e os seus pares. (2012, p. 5, grifo nosso).
\end{abstract}

O trecho destacado traz para a discussão o impacto das políticas de acesso na qualidade do Ensino Superior, pensando na aprendizagem e na formação profissional dos sujeitos que agora se inserem neste nível de ensino. Algumas questões emergem para reflexão: Para além do acesso, as políticas estão garantindo oportunidades de aprendizagem e permanência na Universidade para todos? Estaremos reproduzindo o fracasso escolar, agora em larga escala também no Ensino Superior? Como a falta de qualidade da Educação Básica tem afetado a aprendizagem no Ensino Superior? Como a dinâmica curricular está sendo pensada para garantir a inclusão no contexto das aprendizagens? Como os serviços de apoio pedagógico e assistência estudantil estão sendo equipados para atendimento das novas demandas?

\title{
Considerações finais
}

O percurso histórico do Ensino Superior no Brasil aponta que o desenvolvimento deste nível de ensino deu-se de forma tardia, e em seu princípio a falta de políticas efetivas 
contribuiu para a acentuação do caráter excludente que se consolidou ao longo da história da educação brasileira. Contudo, as recentes políticas de ampliação do acesso ao Ensino Superior no Brasil trazem impactos positivos para a diminuição de desigualdades educacionais regionais, sociais, raciais, impactando sim nos processos de inclusão social das populações marginalizadas através da democratização do acesso em IES públicas e privadas.

Porém, apenas garantir o acesso não é suficiente para se promover a redução das desigualdades sociais, uma vez que existem outros mecanismos excludentes por dentro e por fora das IES que precisam ser alvo de políticas planejadas e articuladas com as já em execução, para que as mesmas se constituam de modo potente. É importante destacar que neste cenário se faz necessário hoje: maior garantia de assistência estudantil aos estudantes de baixa renda; o repensar constante da organização curricular e metodológica de modo a contemplar as carências formativas trazidas pelos estudantes, bem como a implementação de medidas mais efetivas para a melhoria da qualidade da Educação Básica no país, potencializando assim o desenvolvimento acadêmico dos futuros universitários.

Se a partir das políticas de interiorização e expansão do Ensino Superior garantimos o acesso, é preciso pensar o público que estamos recebendo, especialmente nas novas IES, e promover ações que concretizem a permanência e a formação qualificada. Situa-se aí um grande desafio no âmbito da democratização do Ensino Superior: a inclusão no contexto das aprendizagens, através da qual poderá ser possível a formação dos quadros profissionais necessários ao desenvolvimento do país na atualidade e consequente diminuição das desigualdades sociais.

\section{REFERÊNCIAS}

BRASIL. Lei n. 9.394, de 20 de dezembro de 1996: Lei de Diretrizes e Bases da Educação Nacional. Diário Oficial da União, Brasília, 23 dez. 1996.

BRASIL. Ministério da Educação. Instituto Nacional de Estudos e Pesquisas Educacionais (INEP). Resumo Técnico do Censo da Educação Superior 2013. Brasília, DF, 2014. Disponível em:

http://download.inep.gov.br/educacao_superior/censo_superior/apresentacao/2014/coletiva_c enso_superior_2013.pdf. Acesso em: 12 out. 2016.

CARMO, E. F. et al. Políticas públicas de democratização do acesso ao ensino superior e estrutura básica de formação no ensino médio regular. Revista Brasileira de Estudos Pedagógicos (online), Brasília, v. 95, n. 240, p. 304-327, maio/ago. 2014. Disponível em: http://www.scielo.br/pdf/rbeped/v95n240/04.pdf. Acesso em: 20 jan.2017. 
DOURADO, L. F. Políticas e gestão da educação superior no Brasil: múltiplas regulações e controle. RBPAE, v.27, n.1, p. 53-65, jan./abr. 2011.

DOURADO, L. F. A interiorização da educação superior e a privatização do público.

Goiânia: Ed. UFG, 2001.

FÁVERO, M. L. A. Autonomia universitária no Brasil: uma utopia. EPAA, v. 7, n. 24, 1999.

FONSECA, J. J. S. Metodologia da pesquisa científica. Fortaleza: UEC, 2002.

OLIVEIRA, R. P. Reformas educativas no Brasil na década de 90. In: CATANI, A. M.;

OLIVEIRA, R. P. (Orgs.). Reformas educacionais em Portugal e no Brasil. Belo

Horizonte: Autêntica, 2000. p. 77-94.

SANTOS, A. P.; CERQUEIRA, E. A. Ensino superior: trajetória histórica e políticas recentes. 2009. Disponível em: http://www.ceap.br/material/MAT14092013162802.pdf. Acesso em: 8 dez.2015.

SIMÕES, J. L.; MELLO NETO, R. D. Políticas de expansão do ensino superior no Brasil: Reuni versus ProunI. 2012. Disponível em:

http://www.anpae.org.br/seminario/ANPAE2012/Textos/JoseLuisSimoes.pdf. Acesso em: 10 de dez. de 2015.

VIEIRA, R. B. B. Educação superior no contexto nacional: políticas, tensões e desafios. 2007. Disponível em: https://cavi.prodirh.ufg.br/up/65/o/politicas_ppgfe.pdf. Acesso em: 9 dez.2015.

ZAGO, N. Do acesso à permanência no ensino superior: percursos de estudantes universitários de camadas populares. Revista Brasileira de Educação, Rio de Janeiro, v.11, n. 32, p. 226-237, 2006.

\section{Como referenciar este artigo}

CARNEIRO, Luci Annee Vargas; BRIDI, Fabiane Romano de Souza. Políticas Públicas de Ensino Superior no Brasil: um olhar sobre o acesso e a inclusão social. Revista IberoAmericana de Estudos em Educação, Araraquara, v. 15, n. 1, p. 146-158, jan./mar. 2020. eISSN: 1982-5587. DOI: https://doi.org/10.21723/riaee.v15i1.12059

Submetido em: 10/01/2019

Aprovado em: 26/03/2019

Revisões requeridas: $30 / 06 / 2019$

Publicado em: 02/01/2020 